\title{
Day case adenotonsillectomy for paediatric obstructive sleep apnoea: A review of the evidence
}

\section{Deutsch PG, Wijayasingham G, Jindal M}

The Dudley Group of Hospitals NHS foundation Trust

Introduction \& Background

Adenotonsillectomy is one of the most commonly performed ENT procedures in the paediatric population. The leading indication for this in the UK is obstructive sleep apnoea (OSA) ${ }^{1}$. Adenoidectomy and tonsillectomy are frequently performed safely as day case procedures for otitis media with effusion and recurrent tonsillitis ${ }^{2}$. We have learnt from a breath

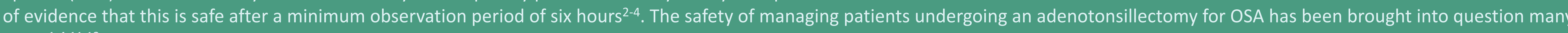
times ${ }^{1-4,11,12}$

Here we review the evidence supporting or refuting the safety of day case paediatric adenotonsillectomy for OSA. We will identify if there are different patient groups that are more suited to day case management compared to planner overnight stays.

Methods

A Literature search was undertaken using NICE evidence journals and databases including EMBASE, PubMed, Medline and Google scholar.

Search terms: Adenoidectomy, tonsillectomy, adenotonsillectomy, day case, paediatric, obstructive sleep apnoea and complications.

Inclusion Criteria: Papers dating from 2004 to 2017 available in English considering paediatric ( $3-17$ years) adenotonsillectomy for OSA.

Exclusion Criteria: Papers considering cohorts with multiple co-morbidities.

Articles were screened by reviewing the titles and abstracts and the papers included were obtained and reviewed in full.

\begin{tabular}{|l|l|l|l|l|l|l|} 
& $\begin{array}{l}\text { Total cohort } \\
\text { size }\end{array}$ & $\begin{array}{l}\text { No co } \\
\text { morbidities }\end{array}$ & $\begin{array}{l}\text { Day case } \\
\text { procedures }\end{array}$ & $\begin{array}{l}\text { Overnight } \\
\text { stays }\end{array}$ & $\begin{array}{l}\text { Documented } \\
\text { desaturations }\end{array}$ & $\begin{array}{l}\text { Needed medical } \\
\text { intervention }\end{array}$ \\
\hline $\begin{array}{l}\text { Baguley et al } \\
2014\end{array}$ & 100 & $1 / 100$ & $99 / 100$ & $7 / 99$ & ng9 \\
\hline $\begin{array}{l}\text { Gan et al } \\
2015\end{array}$ & 51 & 44 & $0 / 44$ & $44 / 44$ & 7 & $\mathrm{n} / \mathrm{a}$ \\
\hline $\begin{array}{l}\text { Youshani et al } \\
2011\end{array}$ & 202 & 165 & $0 / 165$ & $165 / 165$ & $10 / 202$ & $1 / 202$ \\
\hline $\begin{array}{l}\text { Cooper et al } \\
2013\end{array}$ & 250 & 250 & 236 & 14 & 4 & 5 \\
\hline $\begin{array}{l}\text { E.F Boss et al } \\
2012\end{array}$ & 604 & $\mathrm{~N} / \mathrm{A}$ & $604 / 604$ & $0 / 604$ & $\mathrm{~N} / \mathrm{A}$ & $\mathrm{N} / \mathrm{A}$ \\
\hline $\begin{array}{l}\text { Granell et al } \\
\text { 2004 }\end{array}$ & 1243 & $\mathrm{~N} / \mathrm{A}$ & $\approx 622$ & $0 / 622$ & 4 & 16 \\
\hline
\end{tabular}

\begin{tabular}{|c|c|c|c|c|c|c|c|}
\hline \multicolumn{8}{|c|}{ Table 1. Study details } \\
\hline & Bleeding & $\begin{array}{l}\text { Return to } \\
\text { theatre }\end{array}$ & $\begin{array}{l}\text { Laryngo } \\
\text { spasm/aspira } \\
\text { tion }\end{array}$ & \begin{tabular}{|l|} 
Chest \\
infection/fev \\
er
\end{tabular} & Vomiting & $\begin{array}{l}\text { Pain and poor } \\
\text { feeding }\end{array}$ & Others \\
\hline Baguley et & Nil & NII & 1 & & 1 & & \\
\hline
\end{tabular}

\section{\begin{tabular}{l} 
Baguley \\
al 2014 \\
\hline Gan et al
\end{tabular}}

Gan et

2015

Youshani
al 2011

al 2011 difficul

\begin{tabular}{l} 
Cooper et \\
al 2013 \\
\hline E.f Boss et
\end{tabular}

\begin{tabular}{ll} 
E.F Boss \\
al 2012 \\
\hline
\end{tabular}

al 2012

al 2004

Not known Not known

7(and Not known

difficult

1

1

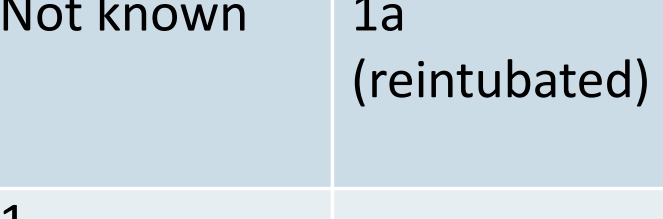

1

78 (within $\quad 36$

24hrs)

Not known

Not kno

\section{Results}

31 relevant papers identified. Only six of these papers included the target population and specifically considered the appropriateness of day case management. One of the papers did not stipulate that the patients were over 3 years old but was included in the review.

Other common inclusion criteria were having a stable family with two adults at home and living in close proximity to the hospital with available transport.

These papers have been summarized in tables 1-3

\begin{tabular}{|l|l|l|l|}
\hline & $\begin{array}{l}\text { Conclusion summary } \\
\text { Baguley et al }\end{array}$ & $\begin{array}{l}\text { Children who are otherwise well with mild to moderate OSA, have a } \\
\text { low risk of respiratory complications following adenotonsillectomy. }\end{array}$ & 6 hours \\
\hline Gan et al & $\begin{array}{l}\text { Same-day discharge for healthy children over } 4 \text { years old having } \\
\text { adenotonsillectomy for mild/moderate OSA appears to be safe. }\end{array}$ & Not stipulated \\
\hline Youshani et al & $\begin{array}{l}\text { Same-day discharge for otherwise-healthy children over } 4 \text { years old } \\
\text { having adenotonsillectomy for mild/moderate OSA appears to be } \\
\text { safe. }\end{array}$ & 6 hours \\
\hline Cooper et al & $\begin{array}{l}\text { Day case adenotonsillectomy may be safely performed in a tertiary } \\
\text { centre for OSA. }\end{array}$ & Not stipulated \\
\hline $\begin{array}{l}\text { Day case adenotonsillectomy for children with OSA appears to be a } \\
\text { safe option for the correct patient group. }\end{array}$ & Not stipulated \\
\hline Granell et al & $\begin{array}{l}\text { Outpatient tonsillectomy is a safe procedure when an appropriate } \\
\text { setting is available. }\end{array}$ & $3-6$ hours \\
\hline
\end{tabular}

Table 3. Conclusions

\section{Discussion}

- OSA occurs in 2-3\% of children and is characterized by an interference of respiratory gas exchange when the child is asleep $5,6,8$.

It is due to failure of the neuromuscular compensatory system to stimulate pharyngeal dilator muscles to maintain airway patency and subsequently ventilation. The commonest cause for OSA in children is adeno-tonsillar hypertrophy ${ }^{12}$

Traditionally paediatric patients undergoing adenotonsillectomies for OSA are observed overnight for pulse oximetry as a proportion of patients with severe OSA have been shown to be sensitive to opiates and anaesthetic gasses causing post-operative respiratory depression ${ }^{12,17,18}$. Added to this, patients under the age of three have proportionally smaller airways and are at risk of airway compromise after adenotonsillectomy.

- Only a small number of publications exist considering the safety of day case management of mild and moderate OSA patients.

- There are multiple benefits of managing these patients as day cases including the child recovering at home, financial, reducing nosocomial infections etc ${ }^{12}$.

- In our literature review we identified six papers associated with day case adenotonsillectomy for paediatric OSA. However only four of these have reviewed day case adenotonsillectomies and the remaining two have only discussed and hypothesised about the safety of day case adenotonsillectomy for OSA.

Overall, a relatively small number of patients had the concerning complication of desaturations and most of the authors said that the children were observed for between four and six hours ${ }^{4,12,14}$.

As such the conclusion from all the included papers is that day case adenotonsillectomy is safe for patients who are free from comorbidities, are over the age of 3 and have means of returning to the hospital should it be required.

Some hospitals have published criteria for day case adenotonsillectomy for OSA in children. The criteria in Nottingham states that the child must have mild or moderate OSA; must be over four and have a six hour observation period with saturations over $93 \%$ on air. They must also have eaten and passed urine.

Other protocols, such as by Sharma et. al have been published. These again state that a child without risk factors and who is well after a period of observation can be discharged as a daycase ${ }^{20}$.

Postoperative severe respiratory complications requiring paediatric intensive care unit facilities (and postoperative ventilation) in children undergoing adenotonsillectomy for OSA do occur, but in a selected, comorbidity free population this appears to be rare ${ }^{12}$.

\section{Conclusions}

There is a growing body of evidence that day case management of a selected group of patients with OSA is a viable option. Added to this in a survey in $200512 \%$ of the ENT surgeons considered day case adenotonsillectomy an option for paediatric OSA. This had increased to 27\% in 2011. In2012, the American Academy of Paediatrics (AAP) published guidelines recommending who required admission after surgery for OSA 21

In light of the evidence, we can conclude that day case adenotonsillectomy for children between 3 and 17 years who are comorbidity free appears to be a safe option. However a large randomised control trial would likely add weight to this conclusion and help change the mind-set of clinicians. 